\title{
Towards a Human-Centred Reference Architecture for Next Generation Balanced Automation Systems: Human-Automation Symbiosis
}

\author{
David Romero $^{1-2}$, Ovidiu Noran ${ }^{2}$, Johan Stahre ${ }^{3}$, Peter Bernus ${ }^{2}$, Åsa Fast-Berglund ${ }^{3}$ \\ ${ }^{1}$ Tecnológico de Monterrey, Mexico \\ david.romero.diaz@gmail.com \\ ${ }^{2}$ Griffith University, Australia \\ O.Noranegriffith.edu.au, P.Bernusegriffith.edu.au \\ ${ }^{3}$ Chalmers University of Technology, Sweden \\ johan.stahre@chalmers.se, asa.fasth@chalmers.se
}

\begin{abstract}
Human-centricity in manufacturing is becoming an essential enabler to achieve social sustainable manufacturing. In particular, human-centric automation can offer new means to increase competitiveness in the face of new social challenges for the factories of the future. This paper proposes a HumanCentred Reference Architecture that can structure and guide efforts to engineer Next Generation Balanced Automation Systems featuring adaptive automation that take into account various criteria in the operating environment such as time-lapse, performance degradation, age-, disability- and inexperience-related limitations of operators to increase their working capabilities.
\end{abstract}

Keywords: Balanced Automation Systems, Human-Centred Manufacturing, Reference Architecture, Level of Automation, Social Sustainability.

\section{Introduction}

According to the European Factories of the Future Research Association (EFFRA) Roadmap 2020, human-centricity will be a prerequisite for the factories of the future seeking to increase flexibility, agility and competitiveness in the face of new social challenges (e.g. demographics). Thus, future manufacturing enterprises will need to be proficient in assisting ageing, disabled and apprentice operators by using evolved information and communication technology capabilities in order to enhance their understanding and thus enable better execution of advanced manufacturing operations [1]. Importantly, this endeavour is likely to require the dynamic (re-)configuration of automation levels driven by the operator execution limitations (gaps) in advanced production management systems in order to enhance competitiveness and compensate for age-, disability-, and inexperience-related limitations of operators to increase their working capabilities.

In this paper, the authors contrast the Tayloristic paradigm of Balanced Automation Systems characterised by a selected mix of independent automated activities and human activities, having humans at subservient roles to machines and automation (e.g. supervisors [2]), towards a human-automation symbiosis [3], or Next Generation Balanced Automation System - characterised by the cooperation of machines and automation with humans, and designed not to replace the skills and abilities of humans, but rather to assist humans in being more efficient [3]. 
The authors explore the bodies of knowledge of intelligent (smart) automation systems [4] and the Enterprise Architecture discipline [5] [6] to propose a HumanCentred Reference Architecture for engineering the Next Generation Balanced Automation Systems, featuring adaptive automation [7].

\section{Current Efforts to Evolve Balanced Automation Systems}

The basic principle leading to the envisioned Next Generation Balanced Automation System is human-centricity, meaning that "humans should never be subservient to machines and automation, but machines and automation should be subservient to humans" [2].

According to Tzafestas [3], the human-automation symbiosis necessary to achieve sustainable development in human society can only be secured by the use of intelligent (smart) automation systems and interfaces, where the assumed 'intelligence' allows inclusion of the explicit representation of human goals and plans and thus constitutes the basis of human-machine interaction. Hence, human-centred design should go beyond the traditional human factors that merely focus on helping operators manage their workload in a healthy and safe manner, to a higher humanistic level such as job inclusion and satisfaction.

Furthermore, according to Hancock et al. [8] the idea of having machines and automation adapt to the cognitive and physical demands of humans in a momentary and dynamic manner (adaptive automation) - is one of the most important ideas in the history of human-automation interaction research towards social sustainability ${ }^{1}$ [8] [9]. In this sense, adaptive automation aims to optimise cooperation and to efficiently allocate labour (cognitive and physical) and distribute tasks between the automated part and the humans in the system [10]; importantly, this paradigm also allows the user and/or the machines to modify the level of automation by shifting the control of specific functions whenever predefined conditions are met [11].

Adaptive automation will help improve a manufacturing system performance in a sustainable way by providing different types of automation solutions ranging from pure manual to fully automatic ${ }^{2}$ [12] according to human-centred automation criteria ${ }^{3}$ [13], thus making it possible to rely on humans and automation to jointly achieve

\footnotetext{
${ }^{1}$ Social Sustainability - "the freedom to choose at any stage in life between different forms of work (work arrangements, field of work) or lifestyles, while being at all times entitled to individual social security" [8].

${ }^{2}$ Levels of Automation - "the allocation of physical and cognitive tasks between resources (humans and technology), described as discrete steps from 1 (totally manual) to 7 (totally automatic), forming a 7 by 7 levels of automation matrix containing 49 possible types of automation solutions" [12].

${ }^{3}$ Criteria - 1. Allocate to the human the tasks best suited to the human, and allocate to the automation the tasks best suited to it 2. Keep the human operator in the decision-and-control loop. 3. Maintain the human operator as the final authority over the automation. 4. Make the human operator's job easier, more enjoyable, or more satisfying through friendly automation. 5. Empower or enhance the human operator to the greatest extent possible through automation. 6. Support trust by the human operator. 7. Give the operator computer-based advice about everything he or she should want to know. 8. Engineer the automation to reduce human error and minimize response variability. 9. Make the operator a supervisor of subordinate automatic control systems. 10. Achieve the best combination of human and automatic control, where best is defined by explicit system objectives [13].
} 
production objectives. Essentially, assistance is to be provided in an adaptive and dynamic manner and only when required (i.e. to help an operator in difficulty to perform his/her tasks according to the expected quality of performance). Nevertheless, the functional state of the operator is to be continuously monitored in order to provide the assistance (aiding) only when necessary and in an unobtrusive manner, i.e. without interfering with the operator's cognitive and physical resources [8]. Thus, one can use advanced trained classifiers [14] relying on psycho-physiological measures (neuroergonomics) in order to determine when an operator actually requires assistance and subsequently to prompt the advanced manufacturing system to provide an appropriate type and level of automation facilitating optimal operator performance.

Hence, the main envisaged goals of adaptive automation are to prevent errors and to reduce out-of-the-loop performance by preserving an adequate level of situation awareness [15] and mental workload, while providing a crucial perception of empowerment materialised into an appropriate level of freedom for the operator [16].

\section{Towards a Human-Centred Automation Reference Architecture}

Tzafestas [3] argues that the design and engineering of cooperation between human and machine or automation system must start from the very beginning and permeate all lifecycle phases of the system. Consequently, human-automation symbiosis engineering projects that design such systems must also implement processes that observe the human-centricity principle, in the context of their own lifecycle.

It is hereby argued by the authors that an optimal way to integrate the lifecycle and human aspects in a human-centred automation reference architecture is by involving the Enterprise Architecture (EA) body of knowledge. For the purpose of this work, authors adopt the mainstream definition of EA, seen as a holistic change management paradigm that bridges management and engineering best practices, providing the "[...] key requirements, principles and models that describe the enterprise's future state [...] EA comprises people, processes, information and technology of the enterprise and their relationships to one another and to the external environment" [17]. Thus, EA considers the socio-technical aspect of systems [18], seen as composed of commitments assumed by voluntaristic people [19] in a complex organisational, political and behavioural context [20] [21]. Therefore, the authors argue that EAbased artefacts such as reference frameworks are capable to provide comprehensive 'shopping lists' of potentially applicable aspects and at the same time integrate all necessary viewpoints (as determined by the stakeholders for the project at hand) in a lifecycle-based set of models ensuring the consistency and sustainability of complex projects (with human-automation symbiosis engineering as a prime example).

In line with this stance, the authors propose the adoption of the Purdue Enterprise Reference Architecture (PERA) [5] and ISO14258 [6] (which places the PERA concepts within a conceptual framework enabling coverage and completeness assessment) as a starting point in building a human-centred automation reference architecture. PERA incorporates an explicit representation of the human role in any type of system and importantly, it also shows the extent of automation, defined as "the absolute extent of pure technologies in their capability to actually automate the tasks and functions of the [...] system" [5] [22]. PERA also shows the relationship between the level of automation (of both the control and information systems and the production/service 
systems), and its effect on the human and organisational element of the enterprise [5].

In the following, the PERA lifecycle architecture (see Fig. 1) will be used in order to reflect a 'master plan' [5] [22] outlining the specifications of a human-automation symbiosis engineering project. The sample business entity selected for this purpose is a typical factory production line.
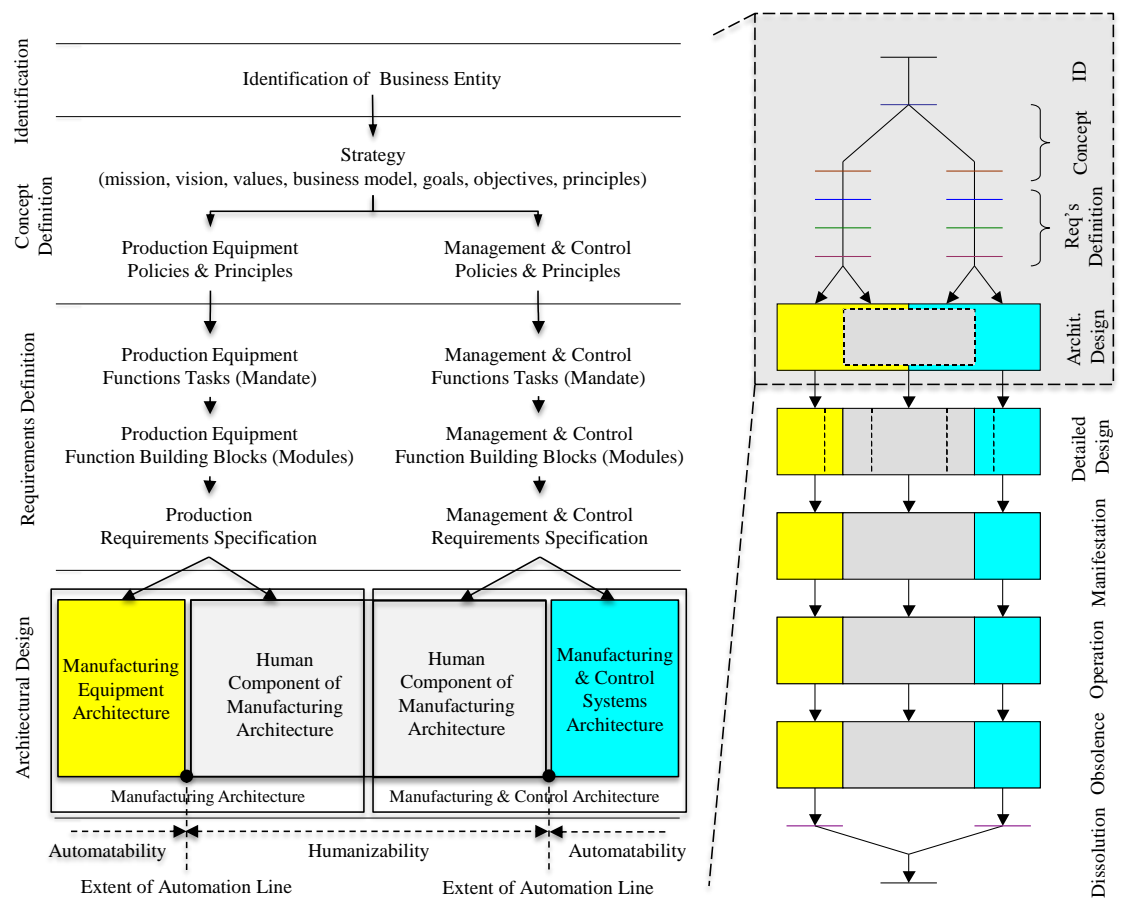

Figure 1. The Purdue Enterprise Reference Architecture (PERA)

[Complete set of lifecycle phases shown on right, current research scope on left]

\subsection{Identification Phase}

At this phase, the architect conducts the typical feasibility (e.g. economic and sociotechnical) and SWOT studies at the production line in question in order to identify potential gains and benefits balanced against costs and risks presented by including the proposed workstation(s) in the human-centric automation engineering program.

\subsection{Concept Definition Phase}

- The Mission is to design and engineer a human-centred production system [23] based on a human-automation symbiosis paradigm that allows operators to feel empowered and in control of their workstation, while also fostering the optimal use of human competencies (knowledge, skills, abilities and behaviours). The system is also to compensate for operators' limitations, thus ensuring a socially sustainable working environment without compromising production objectives. 
- The Vision is to provide adaptive balanced automation systems that comply with mainstream models of human-centred production systems [23] and factories [24].

- Values: Ergonomics, Human Factor, Occupational Health, Safety, Inclusiveness.

- Strategy: To develop a master plan featuring adaptive automation in order to achieve human-automation symbiosis in the workstations of a production system.

\begin{tabular}{|c|c|c|}
\hline $\mathrm{X}_{3}$ & Production Equipment & Management \& Control \\
\hline 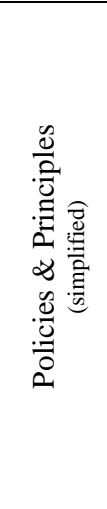 & $\begin{array}{l}\text { - Manufacturing policies } \\
\text { ○ Manufacturing goals } \\
\text { - Operational excellence } \\
\text { - Safety and health } \\
\text { - Inclusiveness } \\
\text { ○ Manufacturing priorities } \\
\text { - Production control } \\
\text { - Quality assurance } \\
\text { - Manufacturing principles } \\
\text { ○ Human-centred manufacturing } \\
\text { ○ Flexible manufacturing } \\
\circ \text { Agile manufacturing } \\
\text { ○ Human-computer interaction } \\
\text { ○ Human-machine interaction }\end{array}$ & $\begin{array}{l}\text { - Occupational health and safety } \\
\text { policies [24] } \\
\circ \text { Regulations } \\
\circ \text { Laws } \\
\text { - Flexible task allocation } \\
\text { principles [25] [26] } \\
\circ \text { Physical task(s) } \\
\circ \text { Cognitive task(s) } \\
\text { - Shared and traded control } \\
\text { principles [27] } \\
\circ \text { Adaptive automation }\end{array}$ \\
\hline
\end{tabular}

\subsection{Requirements Definition Phase}

Special attention must be paid to human-automation interaction requirements [13] [28]:

\begin{tabular}{|c|c|c|}
\hline 7 & Production Equipment & Management \& Control \\
\hline 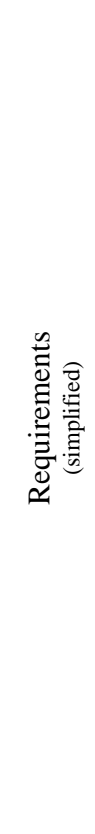 & $\begin{array}{l}\text { - Operator(s) profiling [24] } \\
\circ \text { Anthropometry } \\
\circ \text { Functional capabilities } \\
\text { - Physical } \\
\text { - Cognitive } \\
\circ \text { Knowledge } \\
\text { - Skills } \\
\text { - Expertise } \\
\text { ○ Personal needs } \\
\text { - Production system(s) profiling [24] } \\
\circ \text { Production objectives } \\
\text { - Key performance indicators } \\
\circ \text { Manufacturing Processes } \\
\text { - Flexible assembly operations } \\
\text { - Flexible assembly sequencing } \\
\circ \text { Workplace } \\
\text { - Flexible hand tool(s) } \\
\text { - Flexible machine tool(s) } \\
\text { - Flexible workstation(s) } \\
\circ \text { Governance (for operators) } \\
\text { - Level of authority } \\
\text { - Level of decision making }\end{array}$ & $\begin{array}{l}\text { - Occupational health and safety } \\
\text { strategies [24] } \\
\circ \text { Shift work good practices } \\
\circ \text { Safety equipment } \\
\circ \text { Organisational incentives } \\
\text { - Listing of human-automation } \\
\text { interaction requirements [13] [28] } \\
\text { - Flexible task allocation } \\
\text { strategies [25] } \\
\circ \text { Value stream mapping } \\
\circ \text { Hierarchical task analysis } \\
\circ \text { Levels of automation } \\
\text { - Physical automation } \\
\text { - Cognitive automation } \\
\text { ○ Function allocation decision [26] } \\
\text { - Humanized allocation } \\
\text { - Flexible allocation } \\
\text { - Allocation by users } \\
\text { - Hybrid automation invocation } \\
\text { strategies [27] } \\
\circ \text { Critical-event strategy } \\
\circ \text { Measurement-based strategy } \\
\circ \text { Modelling-based strategy }\end{array}$ \\
\hline
\end{tabular}




\begin{tabular}{|c|c|c|}
\hline 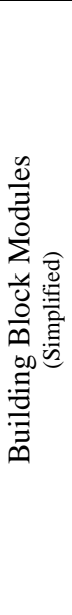 & $\begin{array}{l}\text { - Core technologies (modules) } \\
\circ \text { Manufacturing technology } \\
\circ \text { Automation and control technology } \\
\circ \text { Robotics technology } \\
\circ \text { Human-machine interface technology } \\
\text { - Support technologies (modules) } \\
\circ \text { Information technology } \\
\circ \text { Communication technology } \\
\circ \text { Management technology }\end{array}$ & $\begin{array}{l}\text { - Flexible task allocation modules [25] } \\
\circ \text { Human resources management } \\
\circ \text { Operations management } \\
\text { - Function (task) allocation module - } \\
\text { decision support system [26] } \\
\text { - Hybrid automation invocation } \\
\text { modules [27] } \\
\text { ○ Critical-event strategies: } \\
\text { - Emergency logic } \\
\text { - Executive logic } \\
\text { - Automated display logic } \\
\text { ○ Measurement-based strategy } \\
\text { - Workload measurement } \\
\text { ○ Modelling-based strategy } \\
\text { - Intent inferencing models } \\
\text { - Mathematical models } \\
\text { - Resource models }\end{array}$ \\
\hline 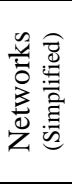 & $\begin{array}{l}\text { - Manufacturing processes flow diagrams } \\
\text { ○ Assembly operations } \\
\circ \text { Assembly sequencing } \\
\text { - Quality criteria (checklist) }\end{array}$ & $\begin{array}{l}\text { - Information flow diagrams } \\
\text { ○ Production measurement } \\
\circ \text { Production control } \\
\text { ○ Operational planning } \\
\circ \text { Operational scheduling }\end{array}$ \\
\hline
\end{tabular}

Bailey's [26] function allocation catalogue provides three human-centred strategies: humanized allocation (priority to the operator over the machine), flexible allocation (according to values, needs and interests) and allocation by users (operator chooses according to conditions), in order to support decision-making from the point of view of the ability of humans to perform.

According to Inagaki [27], in adaptive automation, functions (tasks) can be shared or traded between humans and machines in response to changes in situations or human performance. There are three classes of automation invocation strategies: critical-event, measurement-based and modelling-based.

\subsection{Design Specifications Phase}

The operations involved in a project or production line can be classified according to their purpose into mission fulfilment tasks and information management and control tasks; humans are inherently involved in these all these operations for technological, economic and social reasons.

\begin{tabular}{|c|c|c|c|}
\hline \multicolumn{2}{|c|}{ Mission Fulfilment Task } & \multicolumn{2}{c|}{ Information \& Control Tasks } \\
\hline \multicolumn{2}{|c|}{ Manufacturing Architecture } & Management \& Control Architecture \\
\hline Mechanised Tasks & Human Implemented Tasks & Automated Tasks \\
\hline $\begin{array}{c}\text { Specification } \\
\text { of equipment needed } \\
\text { for adaptive control } \\
\text { tasks of operators }\end{array}$ & $\begin{array}{c}\text { Tasks of } \\
\text { operators working } \\
\text { with the adaptive } \\
\text { automation } \\
\text { system }\end{array}$ & $\begin{array}{c}\text { Tasks of } \\
\text { operators to be } \\
\text { controlled by } \\
\text { the adaptive } \\
\text { automation } \\
\text { system }\end{array}$ & $\begin{array}{c}\text { Specification } \\
\text { design of the adaptive } \\
\text { automation system }\end{array}$ \\
\hline \multicolumn{3}{|c|}{ E Adaptive Automation $\boldsymbol{~}$} \\
\hline
\end{tabular}


According to Inagaki's [27] adaptiveautomation strategies, within the critical-event strategy, functions' allocations change when specific events (called critical-events) occur, e.g. in the human-automation symbiosis. Allocation of functions would not be altered if the critical events did not occur during the human-machine system operation; in this sense, function allocation within a critical-event strategy is adaptive. In measurement-based strategies, functions' allocations are dynamic between operators and machines so that the momentary operator workload (based on psychophysiological measures) can be regulated around an optimal level. In modelling-based strategies, functions' allocations are based on operator performance models (intent inferencing models, optimal (mathematical) models or resource models) that can be used to estimate current and predicted operator state and to infer whether workload is excessive or not.

The ultimate aim of human-automation symbiosis is the achievement of adaptive automation across all workstations of a human-centred production system in order to allow a dynamic and seamless transition of functions (tasks) allocation between humans and machines that optimally leverages human skills to provide inclusiveness and job satisfaction while also achieving production objectives.

\section{Human-Automation Symbiosis Scenarios}

In contrast with the traditional view of automation, adaptive automation is designed to anticipate changes under active control of an operator while maintaining precise control of all background variables not currently of interest [10]; thus, dynamic allocation of task control [25] [26] [27] (in whole or in parts) crossing over various types and levels of automation should be considered to exist in a continuum between the manual and fully automated operational boundaries [11]. There is growing evidence pointing that beyond thinking of adaptive systems as co-workers, humans are increasingly expecting them to display human behaviour. Consequently, adaptive automation ventures into potentially uncharted territories, featuring new challenges for both users and designers that go beyond the traditional ideas of human-computer interaction and system design [29].

In the following sub-sections, the authors introduce three scenarios illustrating the way adaptive automation can help achieve human-automation symbiosis in the context of human-centred production systems [23] and factory models [24]. Naturally, the scenarios presented make use of the adaptive automation aspects structured in Section 3 using PERA, such as shared and traded control principles, flexible task allocation strategies, including levels of automation and function allocation decision and hybrid automation invocation strategies.

In relation to the latter aspect, critical-event function allocation should apply to all scenarios, while measurement-based and modelling-based strategies application may vary in their applicability. This is because the critical-event strategy is aimed to take care of the operator health and safety, as well as of the production objectives. Thus, a critical-event emergency logic involves automation invocation without human involvement e.g. if the operator violates occupation health and safety regulations. A critical-event executive logic invokes the sub-processes leading up to the decision 
to activate automation, with only the final decision requiring the human's approval, e.g. in case of a drop in performance. Finally, a critical-event automated display logic allows all non-critical display findings to be automated in preparation for a particular event (e.g. troubleshooting), so that the human can concentrate on the most important tasks to fix the critical event problem(s).

\subsection{Senior Operators (Aging Challenge)}

In this case, adaptive automation can help a senior operator in a twofold manner: either by increasing automation to compensate for ageing-related limitations and thus help keep with the physical and cognitive quality performance of the job by, or by reducing the level of automation, on request, in order to provide the senior operator with a 'craftsman' experience and increase the level of job satisfaction. Furthermore, the operator may influence the functions allocation within the measurement-based strategy (e.g. by sharing and trading control) outside the 'optimal' level if this action does not compromise personal health and safety and the production objectives. Flexibility in functions allocation is allowed, but at the same time workload will be monitored in real-time in case of physical or mental over-stress (critical-event), so automation can take over. The modelling-based function allocation strategy (utilising models to estimate current and predicted operator state) has a very limited role in this scenario (if at all present) as the focus should be on recreating the craftsman experience or compensating for ageing-related limitations. In addition, by collecting senior operators' knowledge and experience in a particular task, the system could improve the learning curve of new operators by providing adaptive automated expert help [30], as also shown in sub-section 4.3.

\subsection{Operator with a Disability (Inclusiveness Challenge)}

Adaptive physical and cognitive automation can assist an operator with a disability to be able to perform 'normal' tasks (i.e. suitable for workers with no-disabilities). Modelling-based function allocations should be prevalent, based on models obtained from regular disability degree assessments, in order to allow the proper aiding and freedom of automation levels. Measurement-based function allocation could be used to fine-tune the level of automation based on the disabled operator condition.

\subsection{Apprentice Operator (Learning Curve Challenge)}

In this case, apprentice operators can learn new routines with (mainly cognitive) automation assistance. Measurement-based function allocation would play a major role here; as the operator learns and performs operations faster and with fewer errors, the system can gradually surrender automated tasks to the human side. Modelling-based strategies could also be used to achieve stability for specific periods of time (e.g. supporting regular performance reviews). 


\subsection{Summary of the Scenarios}

It must be noted that scenarios such as those shown above vary in content depending on the specific application and may also have overlapping areas, depending on the particular lifecycle phase that the context system finds itself currently in. For example, the necessity to learn new tasks, typical to scenario 4.3 during Operation phase, can also manifest itself in scenarios 4.1 and 4.2, e.g. during Obsolesce and Decommissioning phases when humans may need to be trained in order to be re-assigned, or during Manifestation (Implementation) phase when design changes bringing new functionality for the system require new operator competencies.

\section{Conclusions and Further Work}

The paper has presented the use of modelling artefacts provided by an Enterprise Reference Architecture in order to guide and structure the efforts to define a HumanCentred Reference Architecture for Next Generation Balanced Automation Systems. After populating the areas deemed to be the most relevant to human-automation symbiosis, the paper has briefly illustrated the practical use of these aspects in several typical scenarios.

More research is required in order to delve deeper into the structured aspects provided by PERA, possibly by using other reference architectures that further subdivide these aspects and/or represent them orthogonally in relation to other aspects (e.g. Function, Information, Organisation, Resources, Risk, Economical, Hardware, Software etc. - see ISO15704 Annex A: GERAM [31]). This would provide more detailed guidance as to the available viewpoints and areas that may need to be addressed in specific adaptive automation projects, so as to advance the work towards the creation of a truly human-centred factory model.

\section{References}

1. European Factories of the Future Research Association (EFFRA) Roadmap 2020

2. Rosenbrock, H.H.: Machines with a Purpose. Oxford University Press, Oxford (1990)

3. Tzafestas, S.: Concerning Human-Automation Symbiosis in the Society and the Nature. Int'l. J. of Factory Automation, Robotics and Soft Computing, Issue 3, pp. 16-24 (2006)

4. Ohno, T.: Toyota Production System: Productivity Press (1988)

5. Williams, T.J.: PERA and GERAM: Establishment of the Place of the Human in Enterprise Integration, Proceedings of the 14th International Federation of Automatic Control (IFAC) World Congress, Beijing, China (1999)

6. ISO14258: Industrial Automation Systems: Concepts \& Rules for Enterprise Models (2005)

7. Hancock, P.A., Chignell, M.H.: Adaptive Control in Human-Machine Systems. In P.A. Hancock (Ed.), Human Factors Psychology, pp. 305-345, North Holland: Elsevier Science Publishers (1987)

8. Hancock, P.A., Jagacinski, R.J., Parasuraman, R., Wickens, C.D., Wilson G.F., Kaber, D.B.: Human-Automation Interaction Research: Past, Present and Future. Ergonomics in Design, pp. 9-14 (2013)

9. Litting, B., Griessler, E.: Social Sustainability: A Catchword between Political Pragmatism and Social Theory. Int'l. J. of Sustainable Development, 8(1), pp. 65-79 (2005) 
10. Kay M.: Adaptive Automation Accelerates Process Development. Bioprocess International 4(4), pp.70-78 (2006)

11. Calefato, C., Montanari, R., Tesauri, F.: The Adaptive Automation Design. Human Computer Interaction: New Developments, Kikuo Asai (Ed.), InTech, pp. 141-154 (2008)

12. Fasth-Berglund, A., Stahre, J.: Cognitive Automation Strategy - For Reconfigurable and Sustainable Assembly Systems. Assembly Automation, 33(3), pp. 294-303 (2013)

13. Sheridan, T., Parasuraman, R.: Human-Automation Interaction. Human Factors and Ergonomics, 1(1), pp. 89-129. (2006)

14. Willson, G.F. \& Russel, C.A.: Performance Enhancement in a UAV Task Using Psychophysiologically determined Adaptive Aiding. Human Factors, 49(6), pp. 1005-1019 (2007)

15. Endsley, M. Toward a Theory of Situation Awareness in Dynamic Systems. Human Factors - Human Factors and Ergonomics Society, 37(1), pp. 32-64 (1995)

16. Kaber, D.B., Riley, J.M., Tan, K., Endsley, M.R: On the Design of Adaptive Automation for Complex Systems. Int'l. J. of Cognitive Ergonomics, 5(1), pp. 37-57 (2001)

17. Gartner Research: IT Glossary. http://www.gartner.com/technology/it-glossary/enterprisearchitecture.jsp (2012)

18. Pava, C.: Managing New Office Technology. An Organisational Strategy. New York: Free Press (1983).

19. McGregor, D.: The Human Side of Enterprise. New York: McGraw-Hill (1960)

20. Iivari, J.: A Paradigmatic Analysis of Contemporary Schools of IS Development. European Journal of Information Systems, 1(4), pp. 249-272 (1991)

21. Markus, M.L.: Power, Politics, and MIS Implementation. Communications of the ACM, 26(6), pp. 430-444 (1983)

22. Li, H. and Williams, T. J. (1994). A formalization and extension of the Purdue Enterprise Reference Architecture and the Purdue Methodology (Report 158). West Lafayette, Indiana: Purdue Laboratory for Applied Industrial Control.

23. Charles T., Charles R., Roulstone, A.: Prospects and Conditions for Anthropocentric Production Systems in Britain. APS-Research Papers Series, Vol. 8, Commission of the European Communities, Bruxelles (1990)

24. May, G., Taisch, M., Bettoni, A., Maghazei, O., Matarazzo, A., Stahl, B.: A New Humancentric Factory Model. 12th Global Conference on Sustainable Manufacturing, Procedia CIRP (2014)

25. Fasth-Berglund, Å., Stahre, J.: Task Allocation in Production Systems - Measuring and Analysing Levels of Automation. Analysis, Design, and Evaluation of Human-Machine Systems, 12(1), pp. 435-441 (2013)

26. Bailey, R.W.: Human Performance Engineering. $2^{\text {nd }}$ Ed., London: Prentice-Hall International

27. Inagaki, T.: Adaptive Automation: Sharing and Trading of Control. Chapter 8 - Handbook of Cognitive Task Design, pp. 147-169, Erik Hollnagel Ed. LEA (2003)

28. National Institute of Aerospace (US): Listing of Human-Automation Interaction Requirements, Available at (URL, 2015): http://www.hf.faa.gov/hfportalnew/ Search/DOCs/DTFAWA-10-A-80000\%20Deliverable\%204\%20September\%202010.pdf pp. 100-104 (2010)

29. Scerbo, M.: Adaptive Automation. Neuroergonomics: The Brain at Work, pp. 239-252 (2001)

30. Fast-Berglund, A., Blom, E.: Developing Flexible ICT-tools for Education and Assembly support. 5th International Conference of Applied Human Factors and Ergonomics. Krakow, Poland (2013)

31. ISO/IEC.: Annex A: GERAM. ISO/IS 15704:2000/Amd1:2005: Industrial Automation Systems - Requirements for Enterprise-Reference Architectures and Methodologies (2005) 